\title{
Comparison of Aerosol Optical Depth (AOD) Derived from Ground-Based LIDAR and MODIS
}

\author{
P.W. Chan ${ }^{*}$ \\ Hong Kong Observatory, 134 A Nathan Road, Hong Kong, China
}

\begin{abstract}
The performance and application of AOD products from the Moderate Resolution Imaging Spectroradiometer (MODIS) are studied by comparing with the AOD derived from the ground-based Doppler LIDAR inside the Hong Kong International Airport (HKIA). The backscattered power data of the LIDAR are used to determine the extinction coefficient profile, from which the AOD is calculated. The AOD determined from the LIDAR is found to have good quality by comparing with the AOD measurements from a hand-held sun photometer at HKIA over a period of three months, and as such it is used to study the quality of AOD estimated from MODIS. The 1-km resolution AOD product from MODIS is found to have better correlation with the LIDAR AOD in comparison to the 10-km resolution product. Moreover, since AOD is a column-integrated quantity, its application to the monitoring of the surface visibility changes should be made with caution during the presence of elevated layers of higher aerosol concentrations. Examples of the effects of such elevated aerosol layers are studied.
\end{abstract}

Keywords: Aerosol optical depth, MODIS, LIDAR, Visibility.

\section{INTRODUCTION}

The MODIS AOD products are available in two resolutions over southern China, namely, the standard 10-km resolution level 2 product from National Aeronautics and Space Administration (NASA) and the $1-\mathrm{km}$ resolution product based on previous field studies of AOD using sunphotometer measurements [1]. They have been widely used for the monitoring of visibility in day-to-day weather forecasting. The performance of these AOD products is examined in this paper by comparing with the AOD derived from Range-height Indicator (RHI) scan of a Doppler LIDAR at the Hong Kong International Airport (HKIA, location in Fig. (1)). This LIDAR is mainly used to make wind measurements for the monitoring of low-level windshear and turbulence. It also gives backscattered power data, which could be combined with the visibility measurements from forward scatter sensors at HKIA (locations in Fig. (1)) to produce the extinction coefficient profile and thus the AOD.

AOD is a column-integrated quantity. Besides the aerosol concentration near the surface, it could be affected by the presence of elevated aerosol layers within the boundary layer or even in the middle troposphere. The RHI scans of the LIDAR are able to reveal the changes of the vertical profile of aerosol concentration. The effect of elevated aerosol layer on the application of AOD to the monitoring of surface visibility is examined in this paper through examples of the LIDAR's vertical scans.

*Address correspondence to this author at the Hong Kong Observatory, 134A Nathan Road, Hong Kong, China; E-mail : pwchan@hko.gov.hk

\section{CALCULATION OF LIDAR AOD}

The RHI scans of the LIDAR in the azimuth angle of 258 degrees from the north are used in this study. This scan is only made up to an elevation angle of 45 degrees from the ground (Fig. 2a). Four beams with the elevation angles between 38 and 40 degrees are used in the retrieval of the extinction coefficient profile $\sigma(z)$. The backscattered power data and the signal-to-noise ratio (SNR) of the four beams at each height are averaged. Following [2], the average backscattered power profile with range correction $S(r)$ (where $r$ is the slant range from the LIDAR) are employed to retrieve the extinction coefficient profile by Klett's algorithm:

$$
\sigma(r)=\frac{\exp \left[\left(S(r)-S_{m}\right) / k\right]}{\left\{\sigma_{m}^{-1}+\frac{2}{k} \int_{r}^{r_{m}} \exp \left[\left(S\left(r^{\prime}\right)-S_{m}\right) / k\right] d r^{\prime}\right\}}
$$

for $r$ less than a reference distance $r_{m}, S_{m}=S\left(r_{m}\right), \sigma_{m}=\sigma\left(r_{m}\right)$ and $k$ a constant depending on LIDAR wavelength and the properties of the aerosol. As in the previous studies (e.g. Chan et al. (2007)), the constant $k$ is taken as 1. The SNR threshold for the retrieval is taken as $-10 \mathrm{~dB}$.

For comparison with MODIS AOD at $550 \mathrm{~nm}$, the $\sigma(r)$ determined from Eq.(1) above is converted to the extinction coefficient profile $o^{\prime}(r)$ of this visible wavelength from the wavelength of the LIDAR $\lambda=2022 \mathrm{~nm}$ using the following formula [2]:

$$
\frac{\sigma}{\sigma^{\prime}}=\left(\frac{0.55}{\lambda}\right)^{1.3}
$$




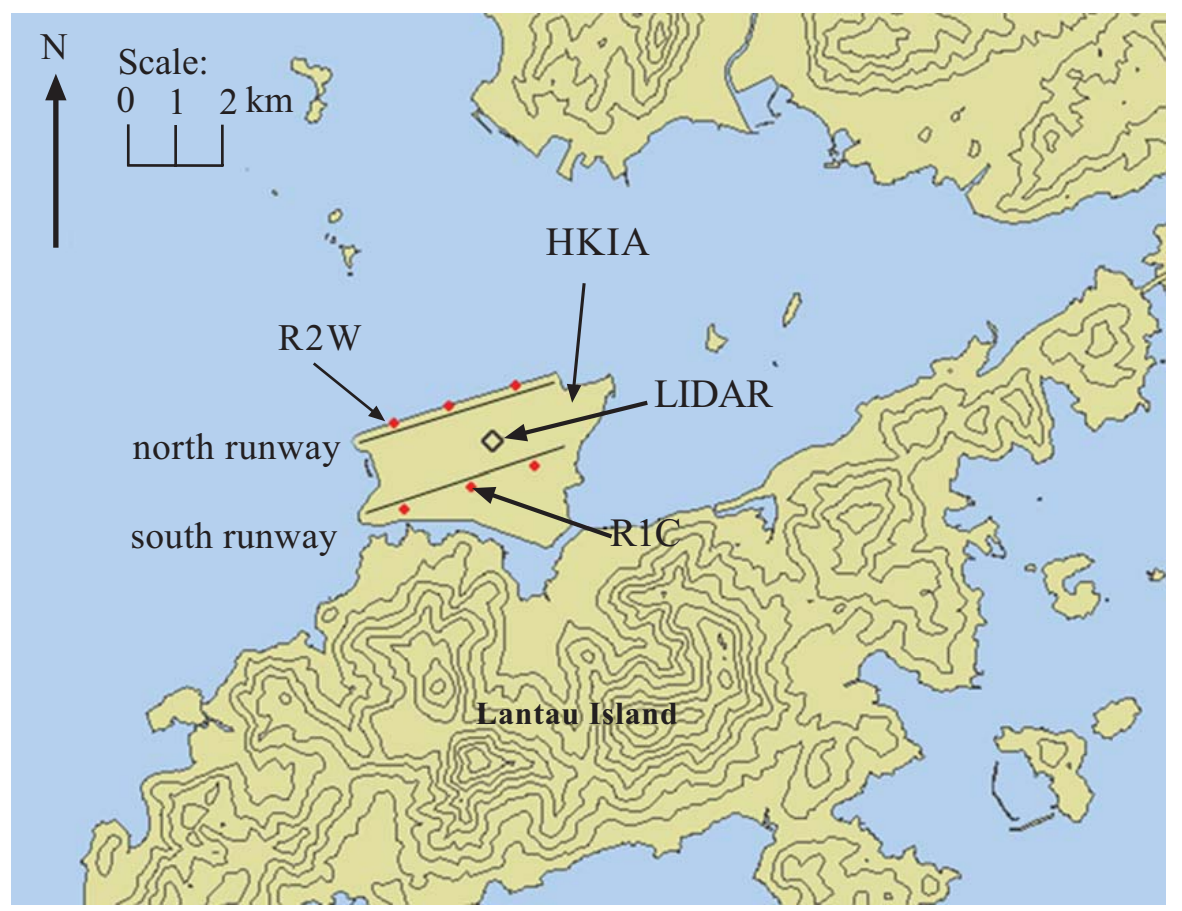

Fig. (1). Geographical situation near HKIA and the locations of the LIDAR (spade) and the forward scatter sensors (red dots). Height contours: $100 \mathrm{~m}$.

The whole extinction coefficient is then adjusted based on the visibility measured by a forward scatter sensor at HKIA [2]. The visibility measurement from the forward scatter sensor is taken to be a point measurement near the surface and could be used to adjust the whole vertical profile of extinction coefficient determined from the LIDAR in an unambiguous manner. In this study, the visibility data from R1C sensor (i.e. near the middle of the south runway of HKIA, location in Fig. (1)) are employed. Finally, the extinction coefficient profile is integrated from the ground up to a certain height $z_{\max }$ to give AOD:

$A O D=\int_{0}^{z_{\max }} \sigma^{\prime}(z) d z$

It is generally observed from the RHI scans of the LIDAR that the atmosphere is basically free from aerosol above $4 \mathrm{~km}$ and the backscattered power greater than this height is mostly contaminated by system noise. As such, the $z_{\text {max }}$ is taken to be $4 \mathrm{~km}$ in this study. As an example, the extinction coefficient profile obtained from the backscattered profile of Fig. (2a) is given in Fig. (2b). It could be seen that extinction coefficient is nearly zero at around the height of 4 $\mathrm{km}$ or so and the extinction coefficient at such altitudes appears to be quite noisy due to the very weak backscattered signal from the aerosol.

\section{PERFORMANCE OF LIDAR AOD}

The horizontal visibility determined from the LIDAR backscattered power at HKIA in the way discussed in Section 2 above is found to have good correlation with independent visibility measurements from the forward scatter sensor [3]. The quality of AOD from the LIDAR is established here by comparing with hand-held sun photometer measurements of Microtops II. The performance of Microtops II in the determination of AOD has been studied in [4]. The same model of sun photometer has been used at HKIA since October 2008. It has been calibrated at the factory before being used in Hong Kong. According to the manufacturer, the AOD measurement from Microtops II has an accuracy of 0.01 .

The sun photometer AOD data at $500 \mathrm{~nm}$ over a threemonth period, namely, October 2008 to January 2009, are considered in the present paper. The comparison results with LIDAR AOD data at $550 \mathrm{~nm}$ are given in Fig. (3). In view of the uncertainty associated with both the AOD measurement from Microtops II and AOD estimate from the LIDAR, total least square is used in studying the correlation between the two datasets, following the method described in [5]. The slope of the best-fit straight line to the data points is close to 1.08 , the $y$-intercept close to -0.05 , and the correlation coefficient reasonably high (0.84). The root-mean-square difference between sun photometer AOD and LIDAR AOD is about 0.16. This is higher than the values given in [4], probably because of the use of data over a much longer period (about 3 months) in this paper. In other studies with Raman LIDAR, e.g. [6,7], the difference between sun photometer measurements and LIDAR measurements could reach $0.1-0.2$ occasionally. It is considered that the present comparison results between hand-held sun photometer and the LIDAR are quite comparable with those reported in the literature.

In Section 2, it is mentioned that a height of $4 \mathrm{~km}$ is used in the calculation of LIDAR AOD. If higher altitude is considered, such as $10 \mathrm{~km}$, the AOD value so calculated would become much higher, reaching about a factor of 3 larger (not shown). The discrepancy with AOD measurements from the hand-held sun photometer becomes unreasonably large. This is because of the noise of the 

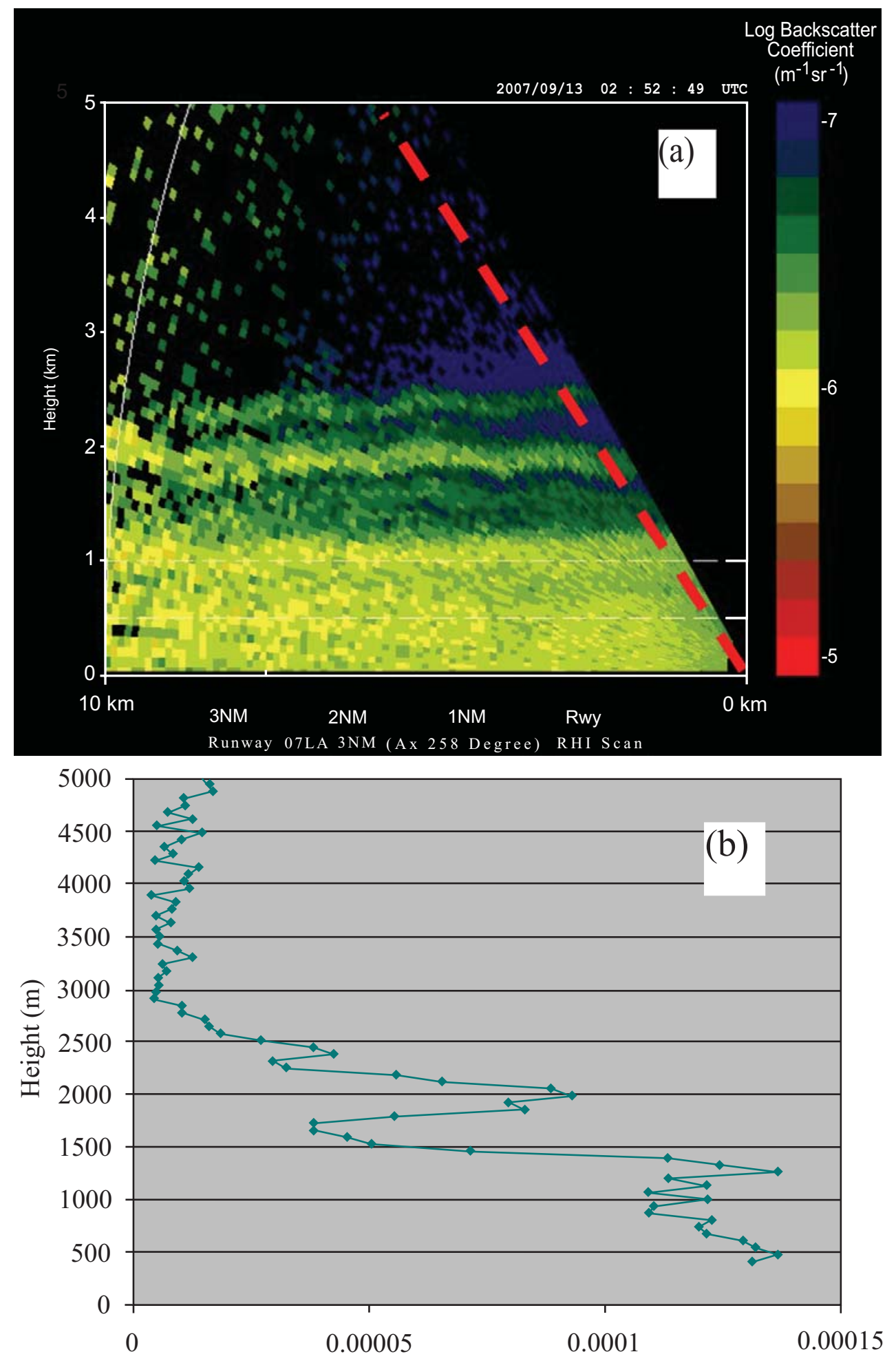

Extinction coefficint $\left(\mathrm{m}^{-1}\right)$

Fig. (2). (a) RHI scan of backscattered power from the LIDAR at 10:53 a.m., 13 September 2007. The radial of 40-degree elevation angle for calculating LIDAR AOD is shown by a red, broken line. (b) is the profile of extinction coefficient derived from the LIDAR.

LIDAR at higher-altitude measurements with the relatively small amount of aerosols over there. The comparison with sun photometer data thus establishes once again the use of the maximum altitude of $4 \mathrm{~km}$ in the calculation of AOD based on the LIDAR at HKIA.

\section{COMPARISON BETWEEN MODIS AND LIDAR AOD}

With the quality of LIDAR AOD (as discussed in Section 2 ) established by comparison with sun photometer data, it is used to study the performance of AOD estimated from 


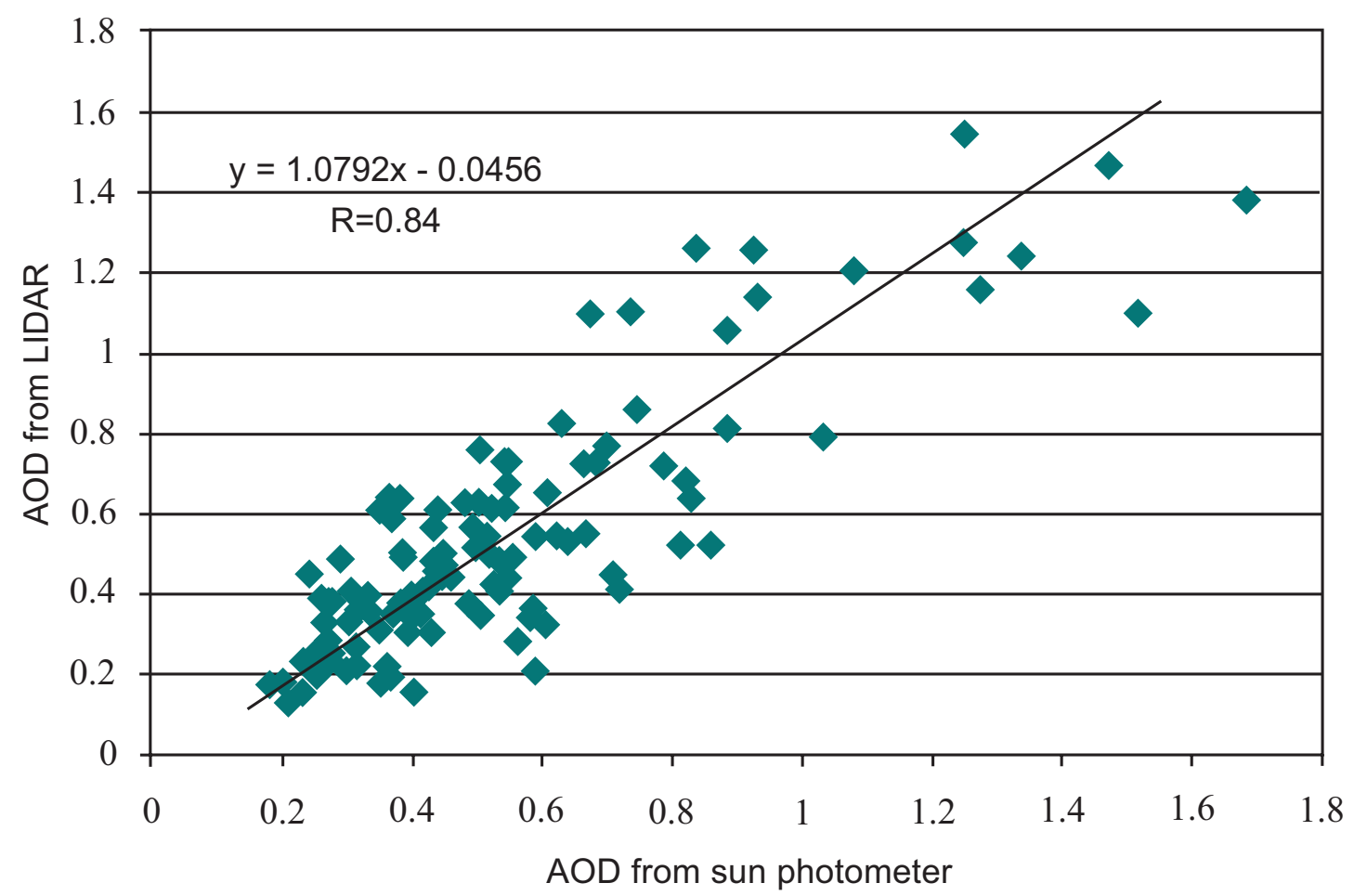

Fig. (3). Comparison between AOD measured by a hand-held sun photometer and that determined from the LIDAR between October 2008 and January 2009.

MODIS. The AOD values near HKIA at $10-\mathrm{km}$ and $1-\mathrm{km}$ resolutions are compared with that obtained from the LIDAR at about the same time in Fig. $(4 \mathbf{a}, \mathbf{b})$ respectively. Once again, due to uncertainty in both the MODIS AOD and LIDAR AOD, total least square is used to study the correlation between the two datasets. The 1-km MODIS AOD turns out to have better correlation with the LIDAR AOD than the $10-\mathrm{km}$ MODIS AOD, namely, a correlation coefficient of 0.78 for $1-\mathrm{km}$ MODIS AOD being greater than that of 0.66 for $10-\mathrm{km}$ MODIS AOD. From Fig. (4b), it could been seen that the MODIS 1-km AOD in general has larger value than LIDAR AOD because there are more data points lying below the 1:1 straight line. The reason for this over-estimation of AOD from MODIS is not clear. Similar over-estimation is also seen in the study of MODIS AOD for other coastal areas of China [8]. The present comparison results, especially for $1-\mathrm{km}$ resolution MODIS data, are quite comparable with those reported in the literature, e.g. [9] on AOD retrieved from MODIS at $500 \mathrm{~m}$ resolution and comparison with AERONET data.

\section{EFFECT OF ELEVATED AEROSOL LAYERS ON THE APPLICATIONS OF AOD}

An elevated layer of aerosol with high concentration may appear at times higher up in the boundary layer or even in the middle troposphere. This could lead to a larger value of AOD, which may not be necessarily associated with deterioration in surface visibility. The RHI scan of the LIDAR gives the vertical distribution of backscattered power, which is related to aerosol concentration, and could be useful in the interpretation of the changes of AOD. An example is given in Fig. (5). Higher concentration of aerosol appeared between 2 and $4 \mathrm{~km}$ above ground in the early afternoon of 1 September 2007 (Fig. 5a). On the other hand, the boundary layer had very low concentration of aerosol only. The MODIS (Fig. (5b, c) and the LIDAR AOD values over HKIA are consistent with each other - both are at the rather large value of $\sim 0.6-0.7$. The surface visibility reported at HKIA was $29 \mathrm{~km}$ at 1 p.m. HKT (= UTC +8 hours) on that day. The source of the elevated aerosol layer requires further study. The higher value of backscattered power between 2 and $4 \mathrm{~km}$ above ground does not seem to be due to clouds because, from the MODIS true-colour imagery, there were no clouds on the western part of the Hong Kong International Airport which was the LIDAR's RHI scanning area (Fig. 5d).

Another example is given in Fig. (6). From 10:30 a.m. to 2 p.m. of 5 October 2006, the AOD measured by the LIDAR increased by $74 \%$ from 0.46 to 0.8 . Similar rise of AOD was also shown in the MODIS data (Fig. 6a). However, in this period the meteorological optical range (MOR) measured by two forward scatter sensors inside HKIA, viz. R1C and R2W (locations in Fig. 1) fell only slightly from $\sim 9000 \mathrm{~m}$ to $\sim 7000 \mathrm{~m}$ (Fig. 6a). The $1-\mathrm{km}$ resolution AOD map from MODIS depicted a significant increase of AOD over many parts of Hong Kong as well as the coastal areas on both sides of Pearl River Estuary (location in Fig. (5b)) in the course of the day (c.f. Fig. 6b, c). By examining the backscattered power data from the RHI scans of the LIDAR, it appears that the AOD increase is contributed more from the rise of aerosol concentration between 1 and $2 \mathrm{~km}$ above ground than that near the surface (c.f. Fig. 6d, e). The higher backscattered values were not due to clouds because, from the MODIS true-colour imageries (not shown), there were no clouds over the LIDAR's RHI scanning area at the times of 

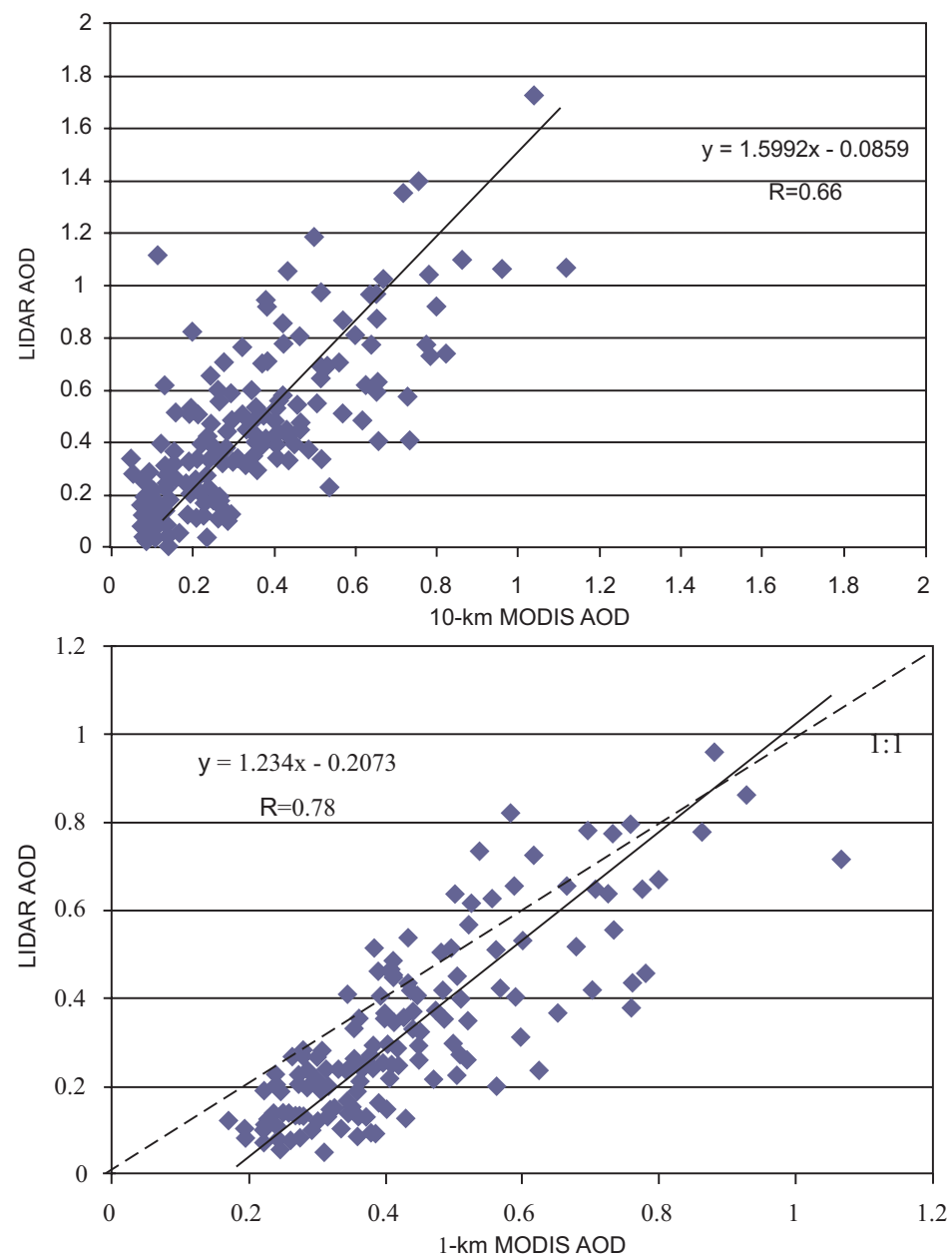

Fig. (4). (a) is the scatter plot of the LIDAR AOD against the standard 10-km resolution MODIS AOD product. The corresponding plot for 1-km resolution MODIS AOD values is given in (b). Period of study: January 2006 to September 2007.
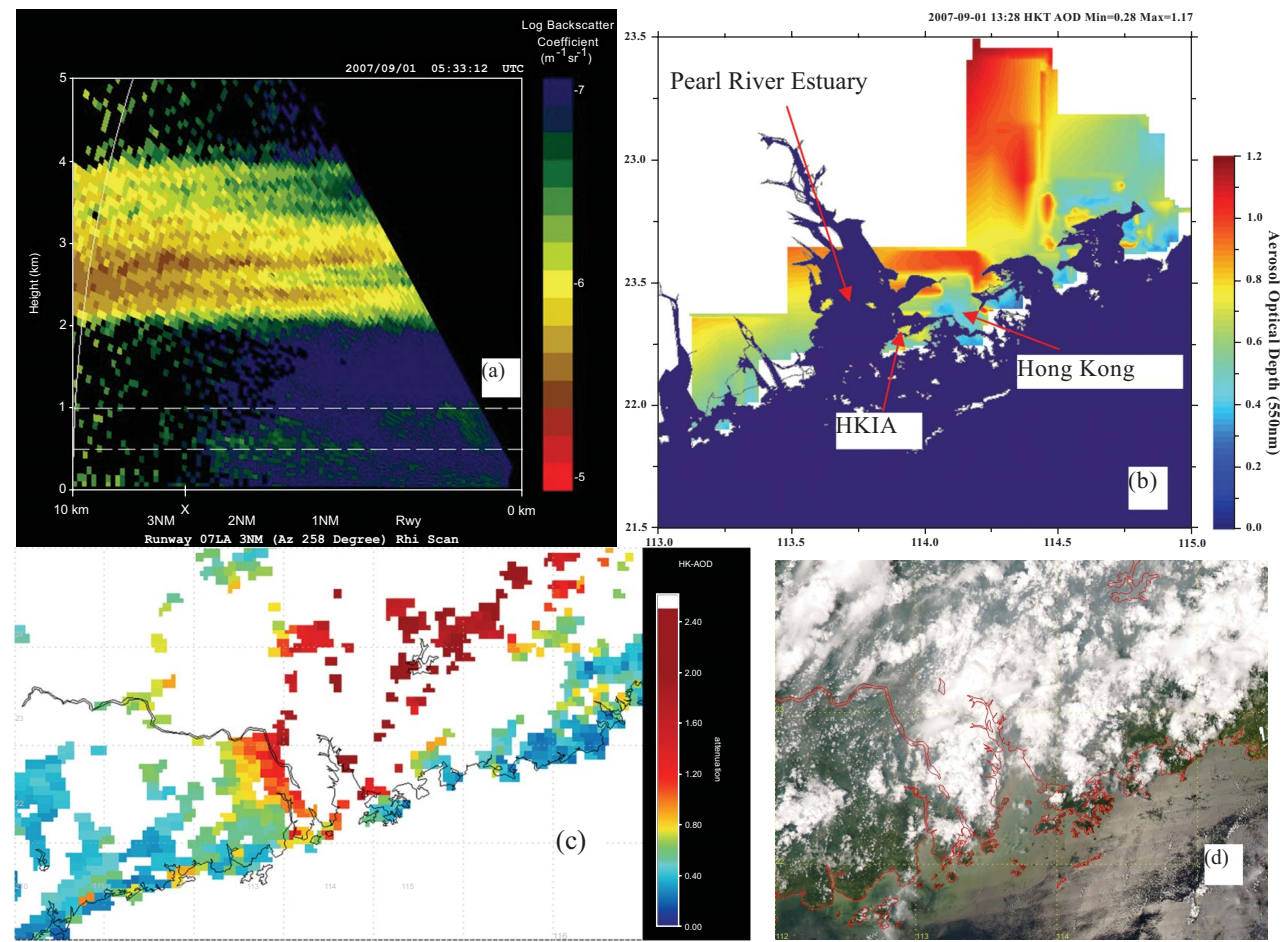

Fig. (5). (a) is the RHI scan of backscattered power data from the LIDAR at 1:33 p.m., 1 September 2007. The MODIS 1-km resolution AOD map at about the same time is shown in (b) and (c) respectively. The true-colour MODIS imagery at that time is given in (d). 


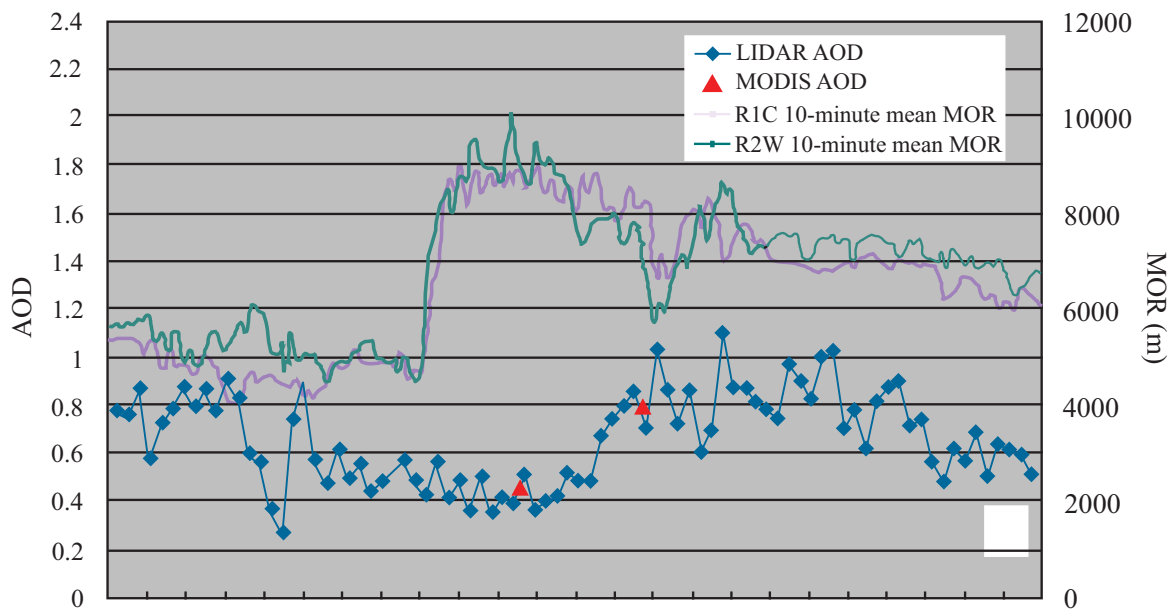

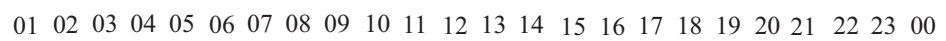

Hong Kong time (hour)
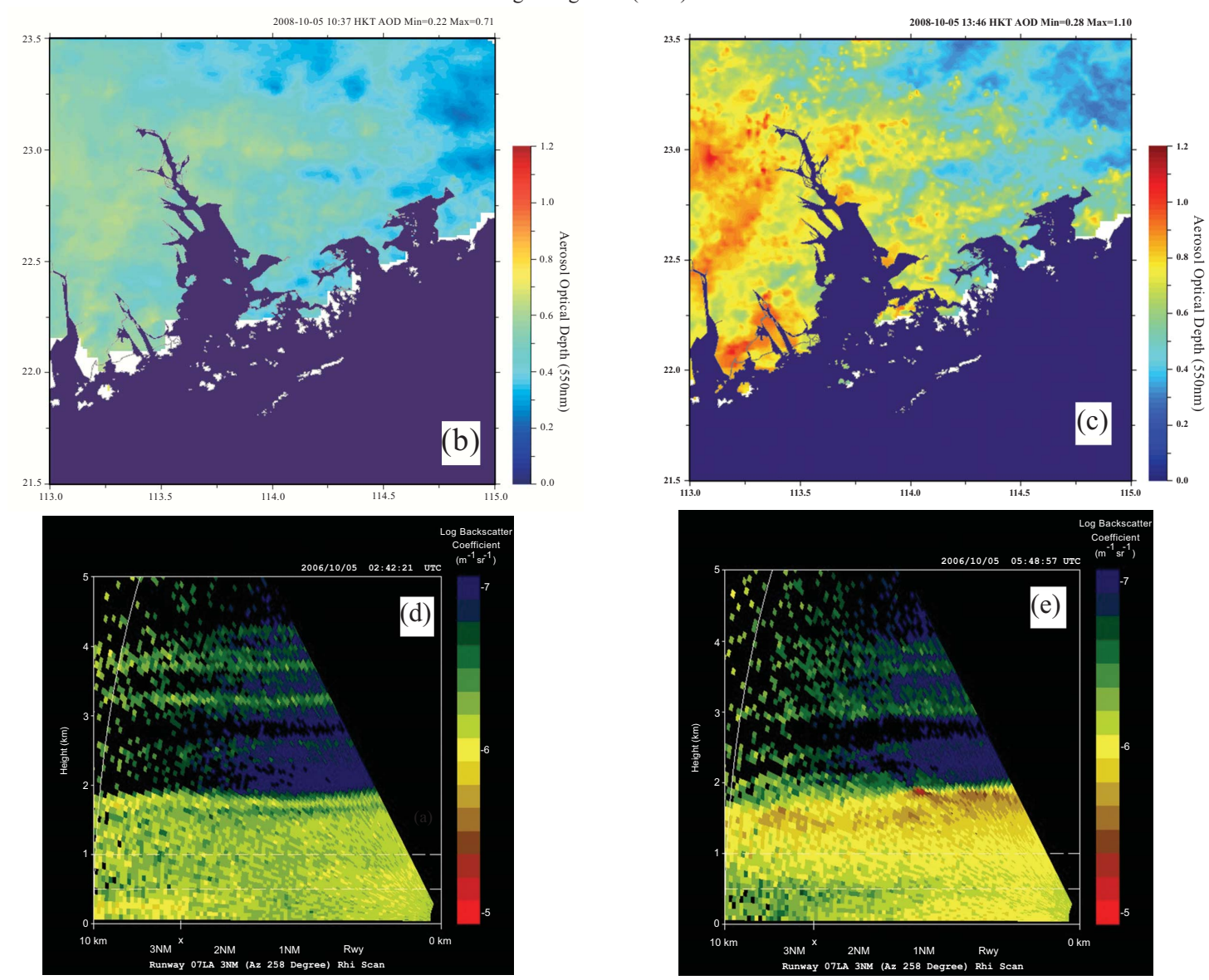

Fig. (6). (a) Time series of LIDAR AOD, MODIS 1-km resolution AOD, and 10-minute mean MOR from two forward scatter sensors at HKIA on 5 October 2006. (b) and (c) are the MODIS 1-km resolution AOD maps at 10:37 a.m. and 1:46 p.m. on that day, and (d) and (e) are the LIDAR's RHI scans of backscattered power data at the corresponding times.

Fig. $(\mathbf{6 b}, \mathbf{c})$. This case again highlights the importance of examining the evolution of the vertical profile of aerosol concentration in interpreting the AOD maps of MODIS.

\section{CONCLUSIONS}

The performance and the application of MODIS AOD products are studied using the AOD derived from the RHI scans of a ground-based LIDAR. The $1-\mathrm{km}$ resolution AOD values derived from MODIS are found to have better correlation with the LIDAR AOD in comparison to the standard $10-\mathrm{km}$ resolution product. In the application of MODIS AOD map in the monitoring of surface visibility distribution, it is noted that elevated aerosol layers may affect the AOD values significantly and it would be useful to interpret the AOD maps together with the vertical profiles of aerosol concentration given by the LIDAR. 


\section{ACKNOWLEDGEMENT}

The author would like to thank the two anonymous reviewers for their useful comments to improve the manuscript.

\section{REFERENCES}

[1] Li CC. Remote sensing of aerosol optical depth by MODIS and Its Application in the regional environmental air pollution studies. $\mathrm{PhD}$ Thesis 2002, Peking University 2002; p. 183.

[2] Chan LM, Chan PW, Cheng YS. Generation of visibility map at the Hong Kong International Airport (HKIA) using LIDAR data. Third Symposium on Lidar Atmospheric Applications. San Antonio, Texas, USA: American Meteorological Society 2007.

[3] Chan PW. Application of LIDAR backscattered power to visibility monitoring at the Hong Kong International Airport: some Initial Results, $6^{\text {th }}$ International Symposium on Tropospheric Profiling 2003; Available at: http://www.weather.gov.hk./publica/reprint/r 519.pdf

[4] Ichoku C, Levy R, Kaufman YJ, et al. Analysis of the performance characteristics of the five-channel microtops II sun photometer for measuring aerosol optical thickness and precipitable water Vapour. J Geophys Res 2002; 107(D13): 4719-35.

[5] Constable C. Geophysical data analysis. Chapter 8, 2005; Available at: http://igpphome.ucsd.edu/ cathy/Classes/SIO223A/index.html.

[6] Ferrare RA, Turner DD, Heilman LA, et al. Raman lidar profiling of water vapour and aerosols over the ARM SGP Site, Symposium on LIDAR atmospheric monitoring. American Meteorological Society 2000.

[7] Ferrare RA, Turner DD, Melfi SH, et al. CART and GFSC Raman LIDAR Measurements of atmospheric aerosol backscattering and extinction profiles for EOS validation and ARM radiation studies, Proceedings of the eighth atmospheric radiation measurement (ARM) science team meeting. 1998; Available at: http://www.arm. gov/publications/proceedings/conf08/

[8] Wang L, Xin J, Wang Y, Li Z, Liu G, Li J. Evaluation of the MODIS aerosol optical depth retrieval over different ecosystems in China during EAST-AIRE. Atmos Environ 2007; 41: 7138-49.

[9] Wong MS, Lee KH, Nichol J, Li Z. Retrieval of aerosol optical thickness using MODIS $500 \times 500 \mathrm{~m}^{2}$, a study in Hong Kong and Pearl River Delta Region. IEEE Trans Geosci Remote Sens 2008; (submitted).

(C) P.W. Chan; Licensee Bentham Open.

This is an open access article licensed under the terms of the Creative Commons Attribution Non-Commercial License (http://creativecommons.org/licenses/by$\mathrm{nc} / 3.0 /$ ) which permits unrestricted, non-commercial use, distribution and reproduction in any medium, provided the work is properly cited. 